RODRIGO ASSUNÇÃO MOURA

\title{
“ESTUDO DAS RELAÇÕES CLONAIS ENTRE AMOSTRAS DE ESCHERICHIA COLI ENTEROPATOGÊNICA ATÍPICA DE ORIGEM ANIMAL E HUMANA"
}

Tese apresentada ao Programa de Pós-Graduação em Microbiologia do Instituto de Ciências Biomédicas da Universidade de São Paulo, para obtenção do Título de Doutor em Ciências.

Área de concentração: Microbiologia.

Orientador: Prof. Dr. Antonio Fernando Pestana de Castro.

Co-Orientador: Prof. Dr. Marcelo Palma Sircili.

São Paulo

2009 


\section{RESUMO}

MOURA, R. A. Estudo das relações clonais entre amostras de Escherichia coli enteropatogênica atípica de origem humana e animal. 2009. $152 \mathrm{f}$. Tese (Doutorado em Microbiologia) - Instituto de Ciências Biomédicas, Universidade de São Paulo, São Paulo, 2009.

EPEC atípica é um patógeno emergente em nosso país. Assim como as EPEC típicas possuem o gene eae e são capazes de produzir lesão attaching and effacing. A principal diferença entre estes patótipos reside no fato de cepas EPEC atípica não possuírem e/ou não expressarem os genes que codificam a fímbria bundle forming pilus (Bfp). No campo epidemiológico, a principal diferença se deve ao fato de amostras EPEC típica terem os seres humanos como principal reservatório, e as EPEC atípica serem isoladas de humanos e animais em freqüências equivalentes, não permitindo a definição de um reservatório. Até o momento, nenhuma pesquisa comparou de modo amplo as relações clonais entre amostras de EPEC atípica isoladas de animais e humanos. O objetivo deste estudo foi verificar se animais podem atuar como reservatórios e fonte de infecção de EPEC atípica para humanos. Para isto, 49 amostras de EPEC atípica e EPEC típica, de diferentes sorotipos, isoladas de humanos e animais (cães, gatos, bovinos, ovinos, coelhos e sagüis) foram estudadas quanto ao seu perfil genotípico pela PCR, e similaridade clonal por Multilocus Sequence Typing (MLST) e Pulsed-Field Gel Electrophoresis (PFGE). Os marcadores de virulência analisados (eae, tir, bfpA, stx1, stx2, stx2f, astA, E-hlyA, espA, espB, espD, espF, sepL) revelaram que cepas de EPEC atípica isoladas de animais possuem potencial para causar diarréia em humanos. Além disso, a análise dos subtipos de eae, tir e genes esp revelaram que a ilha de patogênicidade Locus of Enterocyte Effacement pode ser adquirida a partir de uma única e/ou de diferentes origens. As técnicas MLST e PFGE revelaram que as amostras isoladas de animais e humanos compartilham relações clonais muito próximas, com algumas cepas apresentando perfis MLST e/ou PFGE idênticos. Foi observado, também que cepas de EPEC atípica, bem como outros patógenos de E. coli diarreiogênica (ECD) podem ter se originado da perda e/ou ganho de genes bfp e stx. 
Devido à proximidade clonal encontrada entre as amostras isoladas de animais e humanos podemos inferir que os animais estudados podem atuar como reservatório e fonte de infecção de EPEC atípica para humanos. Pelo fato de humanos possivelmente também atuarem como reservatório de EPEC atípica, ciclos de infecção cruzada entre animais, principalmente de estimação e humanos não podem ser descartados, uma vez que a dinâmica de transmissão entre reservatórios deste patógeno não é muito bem compreendida.

Palavras-Chave: EPEC atípica. EPEC típica. Diarréia. MLST. PFGE. Relação Clonal. Amostras Humanas. Amostras Animais. Reservatório Animal. 


\section{ABSTRACT}

MOURA, R. A. Clonal relationship among atypical enteropathogenic Escherichia coli strains isolated from different animal species and humans. 2009. 152 p. Thesis (PhD in Microbiology) - Instituto de Ciências Biomédicas, Universidade de São Paulo, São Paulo, 2009.

Atypical EPEC is an emergent pathogen in Brazil. Like typical EPEC, these bacterias posses eae gene and are capable to produce attaching and effacing lesions ( $A / E$ lesion). The main difference between these pathotypes is the absence of $\mathrm{pEAF}$ and/or no evidence of expression of bundle forming pilus (Bfp). Epidemiologically these pathotypes diverge from their reservoirs, while typical EPEC strains have humans as their major reservoir, atypical EPEC strains are isolated from both humans and different animal species. Because of its wide spread, it is difficult to determine reservoirs for atypical EPEC strains. Currently there is no research that compared the clonal relationship among atypical EPEC strains isolated from humans and different animal species. The aim of this study was to compare atypical EPEC strains isolated from humans and different animals, including pets, farm animals and wild animals by molecular phylogenetic techniques to verify the role of animals as reservoir and infection source of atypical EPEC for humans. Forty-nine typical and atypical EPEC strains belonging to different serotypes, isolated from humans, pets (cats and dogs), farm (bovines, sheep and rabbits) and wild animals (monkeys) were investigated for virulence markers and clonal similarity by pulsed-field gel electrophoresis (PFGE) and Multilocus Sequence Typing (MLST). The virulence markers analyzed (eae, tir, bfpA, stx1, stx2, stx2f, astA, E-hlyA, espA, espB, $e s p D$, espF, and $s e p L$ ) revealed that atypical EPEC strains isolated from animals have the potential to cause diarrhea in humans. Beside these data, the analysis of eae, tir and esp genes indicated that atypical EPEC strains can acquire the entire LEE region or just single genes of this region from different origins. Close clonal relationship between human and animal isolates was found with MLST and PFGE. These results indicate that these animals act as atypical EPEC reservoirs and may represent sources of infection for humans. Some atypical EPEC strains showed close relationship to typical EPEC strains or 
STEC strains, based on these data some diarrheogenic E. coli may have evolved either by acquisition or loss of stx or bfp genes. Since humans also act as a reservoir of atypical EPEC strains, the cycle of mutual infection between animals and humans, mainly pets and their owners, cannot be ruled out, since the transmission dynamics between the reservoirs are not yet clearly understood.

Key Words: Atypical EPEC. Typical EPEC. Diarrhea. MLST. PFGE. Clonal Relationship. Human Strains. Animals Strains. Animal Reservoir. 
1 INTRODUCÃO 
Cepas Escherichia coli colonizam o trato gastrointestinal de seres humanos e animais poucas horas após o nascimento, e constituem o principal membro anaeróbio facultativo da microbiota intestinal destes organismos (NATARO e KAPER, 1998; KAPER et al., 2004). Esta espécie, pertencente à família Enterobacteriaceae, raramente causa doença em seus hospedeiros, exceto em imunocomprometidos ou quando as barreiras gastrointestinais são rompidas, como nos casos de peritonite (DRASSAR e HILL, 1974; NATARO e KAPER, 1998).

Apesar de seu papel como comensal, algumas cepas E. coli são capazes de causar uma grande variedade de doenças, devido à aquisição de fatores de virulência por transferência horizontal (KAPER et al., 2004). Dentre estas doenças, a diarréia é uma das principais, sendo as $E$. coli diarreiogênicas $(E C D)$ responsáveis por inúmeros surtos de diarréia registrados no mundo (VILJANEN et al., 1990; SMITH et al., 1996; TRABULSI et al., 1996; HEDBERG et al., 1997; MICHINO et al., 1999; JENKINS et al., 2003; YATSUYANAGI et al., 2003; HUSSEIN e BOLLINGER, 2005).

Atualmente são conhecidos seis patótipos de ECD: E. coli enteroinvasora (EIEC); E. coli enterotoxigênica (ETEC); E. coli enteropatogênica (EPEC), subdividida em EPEC típica e EPEC atípica; E. coli produtora da toxina de Shiga (STEC), e seu subgrupo E. coli enterohemorrágica (EHEC); E. coli enteroagregativa (EAEC) e E. coli que adere difusamente (DAEC) (NATARO e KAPER, 1998; KAPER et al., 2004). Dentre estes patótipos, cepas EPEC destacam-se como um importante agente diarreiogênico presente em países em desenvolvimento (OCHOA et al., 2008). 


\subsection{Escherichia coli enteropatogênica (EPEC)}

Os primeiros surtos de diarréia causados por EPEC foram descritos por Bray (1945) no Reino Unido. Este pesquisador identificou grupos de E. coli, sorologicamente distintos, que eram isolados de crianças com diarréia, mas não de crianças sadias. Após este estudo, diversos surtos de diarréia, com altas taxas de mortalidade, foram descritos em países desenvolvidos até o final dos anos 50 (ROWE, 1979; LEVINE e EDELMAN, 1984). Devido aos freqüentes surtos de E. coli registrados naquela época, Neter et al. (1955) criaram o termo EPEC para definir as amostras E. coli que causavam estes surtos.

No final dos anos 50, por razões desconhecidas, grandes surtos de diarréia causados por EPEC deixaram de ocorrer em países desenvolvidos. Infecções causadas por este patógeno ficaram restritas a casos esporádicos em alas hospitalares, até o final da década de 80 (PAULOZZI et al., 1986). Atualmente, surtos causados por EPEC são raros em países desenvolvidos, no entanto, estas bactérias ainda representam um importante agente diarreiogênico em países em desenvolvimento (KAPER et al., 2004; OCHOA et al., 2008).

Estudos baseados em métodos moleculares e fenotípicos estimam que cepas EPEC sejam responsáveis por $10-20 \%$ de todos os casos de diarréia em crianças que vivem em países como Brasil, Chile, México, Tailândia e Tunísia (SCALETSKY et al., 2002; RATCHTRACHENCHAl et al., 2004; FRANZOLIN et al., 2005; VIDAL et al., 2005; AL-GALLAS et al., 2007; ARAUJO et al., 2007; OCHOA et al., 2008; ESTRADA-GARCIA et al., 2009).

As EPEC podem ser classificadas como típicas ou atípicas (TRABULSI et al., 2002). Em 1995, Kaper criou o termo EPEC atípica para definir amostras E. coli que diferiam das EPEC típicas por não transportarem o plasmídeo E. coli Adherence Factor (pEAF) e das EHEC, por não possuírem os genes que codificam a toxina de Shiga (Stx). Atualmente, considera-se que a distinção entre cepas EPEC típica e atípica deve ser baseada na expressão ou não da fimbria bundle forming pilus (Bfp), codificada pelo operon bfp, localizado no pEAF; e na ausência da produção da toxina Stx (KAPER, 1996; BORTOLINI et al., 1999; TRABULSI et al., 2002; OCHOA et al., 2008; ABE et al., 2009; HERNANDES et al., 2009). 
Cepas EPEC atípica pertencem a um grupo diarreiogênico que aumentou muito sua freqüência no Brasil nos últimos anos (FRANZOLIN et al., 2005; BUERIS et al., 2007; MORENO et al., 2008). Em algumas regiões do país, estas bactérias parecem ter substituído as EPEC típicas como principal agente diarreiogênico. Isso indica que no Brasil, assim como ocorreu em países desenvolvidos, está havendo mudança no perfil epidemiológico das EPEC, de típicas para atípicas (TRABULSI et al., 2002; AFSET et al., 2003; FRANZOLIN et al., 2005; BUERIS et al., 2007; MORENO et al., 2008; OCHOA et al., 2008; HERNANDES et al., 2009).

É importante ressaltar que cepas EPEC atípica, há alguns anos, só estavam presentes em países desenvolvidos associadas a surtos esporádicos de diarréia em crianças e adultos (JENKINS et al., 2003; YATSUYANAGI et al., 2003; ROBINSBROWNE et al., 2004). No Brasil estas bactérias estão associadas, principalmente com a diarréia endêmica na criança (SCALETSKY et al., 1999; VIEIRA et al., 2001; FRANZOLIN et al., 2005; BUERIS et al., 2007).

As EPEC típicas e atípicas, assim como outros patótipos de ECD, tendem a formar grupos clonais que compartilham antígenos de superfície que definem seus sorogrupos e sorotipos. São três os antígenos de superfície que caracterizam as $E$. coli, o antígeno $\mathrm{O}$ (lipopolissacarídeo somático da membrana externa), H (antígeno protéico flagelar, responsável pela motilidade bacteriana) e K (polissacarídeo capsular) (NATARO e KAPER, 1998). Os sorogrupos são determinados com base no antígeno $\mathrm{O}$, e os sorotipos com base na combinação dos antígenos $\mathrm{O}$ e H $(\mathrm{O}: \mathrm{H})$. Até o momento, já foram identificados pelo menos de 180 antígenos $\mathrm{O}$ e 60 antígenos $\mathrm{H}$, os quais são determinados por meio de técnicas de soroagluitinação (ØRSKOV, 1984; ROBINS-BROWNE e HARTLAND, 2002).

Em algumas amostras o antígeno flagelar $\mathrm{H}$ não é expresso, sendo estas amostras classificadas como não-móveis (NM ou H-). Para determinar o antígeno $\mathrm{H}$ destas amostras, técnicas de tipagem molecular, baseadas na reação em cadeia da polimerase (PCR) e na utilização de enzimas de restrição foram desenvolvidas (FIELDS et al., 1997; MACHADO et al., 2000). Este tipo de caracterização permite a análise mais precisa de amostras NM em estudos epidemiológicos, e também em estudos de relação clonal, já que diferenças no antígeno $\mathrm{H}$ podem explicar 
diferentes origens clonais (FIELDS et al., 1997; NATARO e KAPER, 1998; MACHADO et al., 2000; RAMOS MORENO et al., 2006).

Segundo a organização mundial de saúde (OMS) os principais sorogrupos de EPEC, também conhecidos como sorogrupos clássicos de EPEC, compreendem: O26, O55, O86, O111, O114, O119, O125, O126, O127, O128, 0142 e 0158 (WHO, 1987). Em revisão, Trabulsi et al. (2002) verificaram diferentes aspectos genotípicos e fenotípicos das EPEC, concluindo que cepas típicas e atípicas constituem dois grupos distintos, representados por diferentes sorotipos. As EPEC típicas pertenceriam aos sorotipos: O55:H[6], O86:H34, O111:H[2], O114:H2, O119:H[6], O127:H6, O142:H6 e O142:H34, enquanto as EPEC atípicas aos sorotipos: O26:H[11], O55:H[7], O55:H[34], O86:H[8], O111ac:H[8], O111:H[9], O111:H25, O119:H2, O125:H6 e O128:H2.

Atualmente, além de cepas EPEC pertencentes aos sorogrupos clássicos, estudos têm demonstrado o isolamento de amostras EPEC atípica pertencentes a sorogrupos diferentes, conhecidos como não-clássicos (KRAUSE et al., 2005; BLANCO et al., 2006; YUSTE et al., 2006; ARAUJO et al., 2007; MOREIRA et al., 2008; MORENO et al., 2008; HERNANDES et al., 2009).

Independentemente dos sorogrupos ou sorotipos a que pertençam às amostras estudadas, existem muitas dificuldades em tentar relacionar sorotipos com patótipos de ECD. Esta dificuldade reside principalmente no fato de algumas amostras, representantes de diferentes patótipos, possuírem sorotipos idênticos. Amostras do sorotipo O26:H[11], por exemplo, podem ser EPEC ou STEC, dependendo da presença ou ausência de fatores de virulência que caracterizam cada um destes patótipos (LEOMIL et al., 2005). Desta forma, a classificação de uma amostra como EPEC, ou como outro patótipo de ECD, deve ser baseada na detecção molecular e fenotípica de seus marcadores de virulência, sendo estas cepas pertencentes ou não a sorogrupos clássicos. 


\subsection{Fatores de virulência das EPEC e lesão attaching and effacing}

A virulência das EPEC típica e atípica está relacionada, principalmente, a sua capacidade em aderir à superfície de enterócitos, e induzir vias de sinalização que resultam no surgimento de lesões intestinais. Estas lesões, inicialmente descritas por Cravioto et al. (1979), reduzem a capacidade de absorção dos intestinos, resultando em quadro de diarréia (NATARO e KAPER, 1998).

As lesões induzidas por estes patógenos são conhecidas como "Attaching and Effacing" (lesão $\mathrm{A} / \mathrm{E}$ ), e caracterizam-se pela aderência intima da bactéria à membrana plasmática apical dos enterócitos, com destruição localizada dos microvilos absortivos. O contato bactéria-enterócito resulta no rearranjo do citoesqueleto da célula eucariota, com a formação de um pedestal rico em actina e outras proteínas do citoesqueleto, logo abaixo do local onde a bactéria se aderiu (MOON et al., 1983; DONNENBERG e KAPER, 1992; NATARO e KAPER, 1998; CLARKE, 2001).

Os fatores necessários para o desenvolvimento da lesão A/E são codificados por uma ilha de patogênicidade cromossômica, de aproximadamente $35 \mathrm{~Kb}$, conhecida como Locus of Enterocyte Effacement (LEE) (JERSE et al., 1990; MCDANIEL et al., 1995; ELLIOTT et al., 1998). A região LEE das EPEC possui 41 Open Reading Frames (ORFS) organizadas em cinco grandes operons, LEE1 LEE5 (ELLIOTT et al., 1998; CLARKE, 2001).

Nos operons LEE1 até LEE3 estão presentes os genes esc (E. coli secretion), responsáveis pela expressão do sistema de secreção do tipo III (T3SS) das EPEC e EHEC. A função deste sistema é translocar proteínas do citoplasma bacteriano diretamente para o citoplasma da célula hospedeira (JARVIS et al., 1995; KENNY e FINLAY, 1995).

No operon LEE4 estão presentes os genes esp (E. coli secreted protein), sepL, entre outros. Os produtos destes genes exercem diferentes funções que auxiliam no desenvolvimento das lesões A/E. No operon LEE5 estão presentes os genes eae ( $E$. coli attaching and effacing) e tir (translocated intimin receptor), codificadores da proteína de membrana externa (OMP), intimina e seu receptor Tir, respectivamente. (JERSE e KAPER, 1991; KENNY e FINLAY, 1995; KENNY et al., 
1996; ABE et al., 1997; KENNY et al., 1997; KENNY e WARAWA, 2001; CLEARY et al., 2004; KAPER et al., 2004; O'CONNELL et al., 2004).

Com relação às características estruturais dos genes presentes na região LEE, observa-se que os genes esc apresentam sequências de nucleotídeos altamente conservadas, enquanto que os genes presentes em LEE4 e LEE5 apresentam sequências variáveis, permitindo a identificação de diferentes subtipos (CHINA et al., 1999; BIELASZEWSKA et al., 2007a; HERNANDES et al., 2009).

EspA, codificada pelo gene espA, é uma proteína filamentosa responsável pela adesão inicial das EPEC, e pela formação de um tubo de translocação na superfície bacteriana. Esta estrutura quando em contato com os enterócitos possui a função de translocar outras proteínas codificadas pela região LEE, bem como algumas proteínas não codificadas nesta região (FRANKEL et al., 1998; KNUTTON et al., 1998; CLEARY et al., 2004; HERNANDES et al., 2009).

Dentre as proteínas translocadas podemos citar EspB (codificada pelo gene espB) e EspD (codificada pelo gene $e s p D$ ) que agem sobre a membrana plasmática da célula eucariota, formando um poro. Este poro permite a passagem dos efetores Tir, Esps, entre outras proteínas diretamente para o citoplasma da célula eucariota (IDE et al., 2001; CREASEY et al., 2003; CLEARY et al., 2004).

As proteínas translocadas possuem diferentes funções, como a desestruturação do citoesqueleto (EspB), perda da resistência transepitelial (EspF), desregulação da função mitocondrial (Map), entre outras (NATARO e KAPER, 1998). As funções de Tir compreendem a autoinserção na membrana da célula eucariota, servindo de receptor para a intimina, e a indução da polimerização de componentes do citoesqueleto eucarioto, induzindo o desenvolvimento do pedestal na superfície do enterócito (KENNY, 1999; KENNY e WARAWA, 2001; WARAWA e KENNY, 2001).

A intimina, descrita por Jerse e Kaper (1991), é uma proteína de 94KDa, cuja função é se ligar ao receptor Tir e induzir a formação do pedestal característico das lesões A/E (KAPER et al., 2004). A porção N-terminal desta proteína é altamente conservada, enquanto sua porção C-terminal é variável, permitindo a identificação de diferentes subtipos (AGIN e WOLF, 1997; ADU-BOBIE et al., 1998a; ADU-BOBIE 
et al., 1998b; OSWALD et al., 2000; JENKINS et al., 2003). A presença de diferentes subtipos de intimina se deve provavelmente, ao fato deste gene sofrer intensa pressão seletiva do sistema imune do hospedeiro (KAPER et al., 2004).

Alguns trabalhos sugerem que os diferentes subtipos de intimina permitem que as EPEC e EHEC tenham tropismo por diferentes tecidos (PHILLIPS e FRANKEL, 2000; FITZHENRY et al., 2002a; FITZHENRY et al., 2002b; MUNDY et al., 2007), no entanto o fato das $E$. coli inserirem seu próprio receptor na célula hospedeira dificulta esta hipótese. Apesar disto, estudos relatam a possibilidade da intimina se ligar em mais de um receptor (FRANKEL et al., 1994; FRANKEL et al., 1995; PHILLIPS e FRANKEL, 2000). Isto pode ser comprovado em estudos, onde a intimina foi capaz de se ligar a nucleolina, uma proteína eucariota (SINCLAIR e O'BRIEN, 2004). Desta forma, a especificidade tecidual seria mediada por outros receptores além da intimina.

O tropismo tecidual mediado por EPEC e outras E. coli que expressam intimina parece ser dependente de múltiplos fatores, no qual o subtipo de intimina pode influenciar na aderência a diferentes tecidos, no entanto mais estudos são necessários (TORRES et al., 2005).

No que se diz respeito a outros fatores de virulência, segundo Trabulsi et al. (2002), as EPEC típicas são mais homogêneas em seu perfil de virulência, quando comparadas com as EPEC atípicas. Com poucas exceções, cepas típicas expressam apenas os fatores de virulência contidos na região LEE e no pEAF. Em contraste, as EPEC atípicas freqüentemente expressam fatores de virulência não contidos na região LEE, como Enteroaggregative E. coli Heat-Stable Enterotoxin (EAST-1), Enterohemolisina (E-hlyA), adesina Afa, entre outros (DULGUER et al., 2003; YATSUYANAGl et al., 2003; LEOMIL et al., 2005; BIELASZEWSKA et al., 2007c; HERNANDES et al., 2009). Desta forma, existem dois tipos de EPEC atípica, aquelas que expressam apenas fatores de virulência codificados pela região LEE, e aquelas que expressam fatores de virulência codificados pela região LEE e em outras regiões do genoma. 


\subsection{Reservatórios de EPEC}

Cepas EPEC típica raramente são isoladas de animais, sendo o homem seu principal reservatório natural (TRABULSI et al., 2002; CARVALHO et al., 2003; NAKAZATO et al., 2004). Em contraste, cepas EPEC atípica são isoladas de humanos e animais, com ou sem diarréia, em freqüências equivalentes, não permitindo a definição de um reservatório para estas bactérias (GOFFAUX et al., 2000; CID et al., 2001; PENTEADO et al., 2002; BEUTIN et al., 2003; CARVALHO et al., 2003; LEOMIL et al., 2003; VETTORATO et al., 2003; AKTAN et al., 2004; NAKAZATO et al., 2004; FRANZOLIN et al., 2005; KRAUSE et al., 2005; LEOMIL et al., 2005; AIDAR-UGRINOVICH et al., 2007).

Diversos estudos associam animais de estimação, de criação e alguns silvestres como possíveis reservatórios e fonte de infecção de EPEC atípica para humanos (CARVALHO et al., 2003; NAKAZATO et al., 2004; KRAUSE et al., 2005; ISHII et al., 2007). Apesar disto, nenhum comparou, de forma ampla, amostras isoladas de humanos e animais por técnicas como Multilocus Sequence Typing (MLST) e Pulsed-Field Gel Electrophoresis (PFGE) para comprovar tais hipóteses.

Origens clonais comuns entre cepas bacterianas isoladas de animais e humanos podem identificar fontes de infecção e reservatórios animais de diferentes patógenos. Estudos neste sentido, envolvendo E. coli foram realizados, principalmente com E. coli uropatogênica (UPEC) (JOHNSON et al., 2008a; JOHNSON et al., 2008b).

Johnson et al. (2008a) compararam cepas UPEC isolada de cães com cepas E. coli extra-intestinal (EXPEC) isoladas de humanos. As cepas isoladas de humanos possuíam as mesmas características genotípicas, filogenéticas e sorotipos que as amostras isoladas de cães. Estes autores concluíram que cepas UPEC isoladas de cães são potencialmente patogênicas para humanos, e que estes animais representam um reservatório destas bactérias.

Em estudo posterior Johnson et al. (2008b) compararam, por Randomamplified Polymorphic DNA (RAPD) e Pulsed-Field Gel Electrophoresis (PFGE), cepas UPEC isoladas animais de companhia e de seres humanos. Nestas análises, os autores concluíram que animais e humanos são colonizados pelos menos clones 
de UPEC e que a transmissão-cruzada destas bactérias entre humanos e animais ocorre.

Estudos com EPEC atípica têm focado, principalmente a comparação entre cepas isoladas de casos de diarréia com cepas isoladas de pacientes saudáveis (AFSET et al., 2008). Faltando desta forma um estudo que esclareça, de forma ampla, as relações clonais existentes entre amostras EPEC atípica isoladas de humanos e animais.

O estudo comparativo entre amostras EPEC atípica isoladas de animais e humanos com e sem diarréia por MLST e PFGE, como foi proposto neste estudo, contribui para identificação de reservatórios e fontes de infecção de EPEC atípica no Brasil e em outros países.

\subsection{Métodos de tipagem molecular para caracterização de cepas bacterianas}

A análise epidemiológica molecular de cepas bacterianas, provenientes de diferentes origens é uma avaliação das relações de parentesco existente entre elas. A principal questão destas análises é saber se diferentes isolados de um determinado patógeno representam a disseminação de um organismo comum ou clone. Neste sentido a epidemiologia sempre tem buscado desenvolver técnicas que proporcionem uma melhor avaliação das relações existentes entre diferentes isolados bacterianos.

Com o advento da Biologia Molecular, nos anos 70, ficou claro que o cromossomo representa a molécula fundamental de identidade das bactérias, tornando possível a criação de novas técnicas epidemiológicas (PERSING e TENOVER, 2004). Nos últimos anos uma grande variedade de técnicas moleculares baseadas no estudo da similaridade dos cromossomos foi desenvolvida, dentre elas se destacam o Pulsed-Field Gel Electrophoresis (PFGE) e o Multilocus Sequence Typing (MLST) (SCHWARTZ et al., 1983; MAIDEN et al., 1998).

O conceito básico das técnicas de tipagem molecular propõe que amostras bacterianas epidemiologicamente relacionadas possuem um precursor comum, desta forma, estudos utilizando estas técnicas permitem uma melhor compreensão 
sobre os mecanismos evolutivos, surgimento de cepas virulentas e reservatórios de cepas bacterianas (PERSING e TENOVER, 2004)

\subsection{Multilocus Sequence Typing (MLST)}

O MLST é uma técnica de caracterização molecular e investigação epidemiológica proposta por Maiden et al. (1998), a qual também tem sido amplamente utilizada para inferência filogenética de espécies bacterianas (MAIDEN et al., 1998; COOPER e FEIL, 2004; NEMOY et al., 2005; HARBOTTLE et al., 2006).

Esta técnica pode ser considerada uma variação do Multilocus Enzyme Electrophoresis (MLEE), pois também se baseia no estudo de diferentes alelos de housekeeping genes. A principal diferença entre estas duas metodologias, é que o MLEE analisa a mobilidade eletroforética de isoenzimas codificadas pelos housekeeping genes e o MLST analisa diretamente as seqüências destes genes, identificando pontos de mutação que caracterizam alelos distintos (HANNAGE et al., 2004).

Diferenças de um único nucleotídeo entre seqüências de um mesmo locus são considerados diferentes alelos (MAIDEN et al., 1998). O conjunto de alelos dos diferentes loci estudados no MLST determina o perfil alélico ou sequence type (ST) de uma cepa bacteriana. Os ST encontrados dentro de uma população bacteriana permitem o estudo comparativo de suas cepas, bem como a inferência filogenética de seus membros (MAIDEN et al., 1998).

Uma das grandes vantagens do MLST é ser uma técnica baseada na seqüência de DNA e não em métodos eletroforéticos, esta característica permite uma análise de dados mais precisa, e também a troca de dados entre diferentes laboratórios com maior precisão, diferentemente das técnicas baseadas em eletroforese (MAIDEN et al., 1998) (HANNAGE et al., 2004).

Com respeito às análises filogenéticas, o MLST tem mostrado eficácia superior em relação ao PFGE. Em alguns estudos envolvendo cepas $E$. coli produtoras de $\beta$-lactmase de espetro estendido, e em outros envolvendo cepas Salmonella enterica, esta técnica conseguiu uma melhor diferenciação entre as 
cepas estudadas em relação ao PFGE (NEMOY et al., 2005; HARBOTTLE et al., 2006). No entanto, comparações deste tipo ainda são controversas, visto que existem estudos que enfatizam a superioridade ou a mesma capacidade de resolução do PFGE nestas relações (LEOMIL et al., 2005; Jl et al., 2006).

\subsection{Pulsed-Field Gel Electrophoresis (PFGE)}

A técnica PFGE, desenvolvida por Schwartz et al. (1983) é considerada a ferramenta "padrão ouro" para diferenciação clonal de diversos patógenos bacterianos (PERSING e TENOVER, 2004). Este método tem se mostrado muito eficiente para identificar clones de $E$. coli que causam os surtos de diarréia (BENDER et al., 1997; LEOMIL et al., 2005; Jl et al., 2006). O principio desta técnica consiste na separação de fragmentos de DNA de alto peso molecular, obtidos pela digestão do DNA genômico da bactéria com enzimas de restrição (GOERING, 2004).

Para separação destes fragmentos é utilizada corrente eletroforética, na qual a direção e intensidade dos pulsos elétricos aplicados são alteradas em diferentes intervalos de tempo. Este tipo de eletroforese permite que fragmentos de DNA de alto peso molecular se separem de melhor maneira em um gel de agarose, quando comparado com resultados obtidos em eletroforese convencional. O perfil de restrição gerado é utilizado para comparação clonal das amostras (SCHWARTZ et al., 1983).

Diferentes metodologias para execução do PFGE já foram descritas, o que impedia a reprodutibilidade e comparação de resultados entre laboratórios. Para uma melhor reprodutibilidade e uniformidade entre laboratórios, foi criado o Prevention PulseNet, por meio da colaboração de diferentes laboratórios do U.S. Centers for Disease Control (CDC) (GOERING, 2004; RIBOT et al., 2006).

O PulseNet definiu alguns aspectos que devem ser seguidos para realização desta técnica. Dentre eles incluem-se: (1) o cromossomo da bactéria deve ser isolado de forma intacta; (2) a qualidade da preparação das amostras deve permitir a ação de enzimas de restrição; e (3) a concentração do DNA deve ser o suficiente para a produção de bandas (GOERING, 2004). 
Outros fatores que podem influenciar em resultados divergentes no PFGE, também foram estabelecidos: tipo de agarose e sua concentração $(0,8$ a $1,0 \%)$; espessura do gel (não deve ser muito fino); escolha do tampão $(0,5 x \mathrm{TBE})$; temperatura da câmara $\left(14^{\circ} \mathrm{C}\right)$; ângulo de reorientação $\left(120^{\circ}\right)$ e campo de força $(6 \mathrm{~V} / \mathrm{cm})$.

A enzima de restrição a ser utilizada deve ser uma endonuclease de corte raro, permitindo que o genoma bacteriano seja cortado em 10 à 30 fragmentos, com tamanhos diferentes e bem distribuídos. 
6 CONCLUSÕES 
- O perfil de virulência encontrado em cepas EPEC (típica e atípica) isoladas de animais é muito semelhante ao encontrado em EPEC (típicas e atípicas) isoladas de humanos, portanto cepas provenientes de animais são potenciais patógenos para seres humanos.

- A presença de fatores de virulência, como a enterohemolisina, em cepas EPEC atípica aumenta a capacidade destas bactérias de causar diarréia em crianças e também adultos.

- A necessidade de utilizar diferentes conjuntos de iniciadores para detecção de genes da região LEE, aliado ao fato de algumas cepas apresentarem subtipos de intimina e tir distintos, indica que as EPEC atípicas adquiriram suas regiões LEE de diferentes origens.

- As análises por MLST e PFGE mostraram que cepas EPEC atípicas isoladas de animais e humanos compartilham origens clonais comuns, sendo possível afirmar que animais atuam como reservatório e fonte de infecção de EPEC atípica para humanos.

- Pelo fato de humanos atuarem como reservatório de EPEC típica, e possivelmente de EPEC atípica, não pode ser descartada a hipótese de que humanos transmitam cepas EPEC para animais.

- Alguns sorotipos de EPEC atípica apresentam relações clonais muito próximas com a STEC EDL933 e outros com a cepa EPEC típica E2348/69, indicando que cepas EPEC atípica se originaram da perda de fatores de virulência característicos destes patótipos e/ou deram origem aos mesmos devido aquisição de fatores de virulência.

- Durante o estudo e investigação de surtos diarréicos causados por EPEC atípica, o papel de animais como possíveis fontes de contaminação devem ser considerados. 
REFERÊNCIAS 
ABE, A.; KENNY, B.; STEIN, M.; FINLAY, B. B. Characterization of two virulence proteins secreted by rabbit enteropathogenic Escherichia coli, EspA and EspB, whose maximal expression is sensitive to host body temperature. Infect. Immun., v.65, p.3547-3555, 1997.

ABE, C. M.; TRABULSI, L. R.; BLANCO, J.; BLANCO, M.; DAHBI, G.; BLANCO, J. E.; MORA, A.; FRANZOLIN, M. R.; TADDEI, C. R.; MARTINEZ, M. B.; PIAZZA, R. M.; ELIAS, W. P. Virulence features of atypical enteropathogenic Escherichia coli identified by the eae(+), pEAF-negative, stx() genetic profile. Diagn. Microbiol. Infect. Dis., v.64, p.357-365, 2009.

ADU-BOBIE, J.; FRANKEL, G.; BAIN, C.; GONCALVES, A. G.; TRABULSI, L. R.; DOUCE, G.; KNUTTON, S.; DOUGAN, G. Detection of intimins alpha, beta, gamma, and delta, four intimin derivatives expressed by attaching and effacing microbial pathogens. J. Clin. Microbiol., v.36, p.662-668, 1998a.

ADU-BOBIE, J.; TRABULSI, L. R.; CARNEIRO-SAMPAIO, M. M.; DOUGAN, G.; FRANKEL, G. Identification of immunodominant regions within the $\mathrm{C}$ terminal cell binding domain of intimin alpha and intimin beta from enteropathogenic Escherichia coli. Infect. Immun., v.66, p.5643-5649, 1998b.

AFSET, J. E.; ANDERSSEN, E.; BRUANT, G.; HAREL, J.; WIELER, L.; $\mathrm{BERGH}$, K. Phylogenetic backgrounds and virulence profiles of atypical enteropathogenic Escherichia coli strains from a case-control study using multilocus sequence typing and DNA microarray analysis. J. Clin. Microbiol., v.46, p.2280-2290, 2008.

AFSET, J. E.; BERGH, K.; BEVANGER, L. High prevalence of atypical enteropathogenic Escherichia coli (EPEC) in Norwegian children with diarrhoea. J. Med. Microbiol., v.52, p.1015-1019, 2003.

AFSET, J. E.; BEVANGER, L.; ROMUNDSTAD, P.; BERGH, K. Association of atypical enteropathogenic Escherichia coli (EPEC) with prolonged diarrhoea. J. Med. Microbiol., v.53, p.1137-1144, 2004.

AGIN, T. S.; WOLF, M. K. Identification of a family of intimins common to Escherichia coli causing attaching-effacing lesions in rabbits, humans, and swine. Infect. Immun., v.65, p.320-326, 1997.

AIDAR-UGRINOVICH, L.; BLANCO, J.; BLANCO, M.; BLANCO, J. E.; LEOMIL, L.; DAHBI, G.; MORA, A.; ONUMA, D. L.; SILVEIRA, W. D.; PESTANA DE CASTRO, A. F. Serotypes, virulence genes, and intimin types of Shiga toxinproducing Escherichia coli (STEC) and enteropathogenic E. coli (EPEC) isolated from calves in Sao Paulo, Brazil. Int. J. Food. Microbiol., v.115, p.297306, 2007. 
AKTAN, I.; SPRIGINGS, K. A.; LA RAGIONE, R. M.; FAULKNER, L. M.; PAIBA, G. A.; WOODWARD, M. J. Characterisation of attaching-effacing Escherichia coli isolated from animals at slaughter in England and Wales. Vet. Microbiol., v.102, p.43-53, 2004.

AL-GALLAS, N.; BAHRI, O.; BOURATBEEN, A.; BEN HAASEN, A.; BEN AISSA, R. Etiology of acute diarrhea in children and adults in Tunis, Tunisia, with emphasis on diarrheagenic Escherichia coli: prevalence, phenotyping, and molecular epidemiology. Am. J. Trop. Med. Hyg., v.77, p.571-582, 2007.

ARAUJO, J. M.; TABARELLI, G. F.; ARANDA, K. R.; FABBRICOTTI, S. H.; FAGUNDES-NETO, U.; MENDES, C. M.; SCALETSKY, I. C. Typical enteroaggregative and atypical enteropathogenic types of Escherichia coli are the most prevalent diarrhea-associated pathotypes among Brazilian children. J. Clin. Microbiol., v.45, p.3396-3399, 2007.

ARCHIE, J. W. A. randomization test for phylogenetic information in systematic data. Syst. Zoo., v.38, p.13, 1989.

BAGCIGIL, A. F.; IKIZ, S.; DOKUZEYLU, B.; BASARAN, B.; OR, E.; OZGUR, N. Y. Fecal shedding of Salmonella spp. in dogs. J. Vet. Med. Sci., v.69, p.775777, 2007.

BENDER, J. B.; HEDBERG, C. W.; BESSER, J. M.; BOXRUD, D. J.; MACDONALD, K. L.; OSTERHOLM, M. T. Surveillance by molecular subtype for Escherichia coli O157:H7 infections in Minnesota by molecular subtyping. N. Engl. J. Med., v.337, p.388-394, 1997.

BEUTIN, L.; KAULFUSS, S.; HEROLD, S.; OSWALD, E.; SCHMIDT, H. Genetic analysis of enteropathogenic and enterohemorrhagic Escherichia coli serogroup 0103 strains by molecular typing of virulence and housekeeping genes and pulsed-field gel electrophoresis. J. Clin. Microbiol., v.43, p.1552-1563, 2005.

BEUTIN, L.; MARCHES, O.; BETTELHEIM, K. A.; GLEIER, K.; ZIMMERMANN, S.; SCHMIDT, H.; OSWALD, E. HEp-2 cell adherence, actin aggregation, and intimin types of attaching and effacing Escherichia coli strains isolated from healthy infants in Germany and Australia. Infect. Immun., v.71, p.3995-4002, 2003.

BEUTIN, L.; MONTENEGRO, M. A.; ORSKOV, I.; ORSKOV, F.; PRADA, J.; ZIMMERMANN, S.; STEPHAN, R. Close association of verotoxin (Shiga-like toxin) production with enterohemolysin production in strains of Escherichia coli. J. Clin. Microbiol., v.27, p.2559-2564, 1989.

BIELASZEWSKA, M.; DOBRINDT, U.; GARTNER, J.; GALLITZ, I.; HACKER, J.; KARCH, H.; MULLER, D.; SCHUBERT, S.; ALEXANDER SCHMIDT, M.; SORSA, L. J.; ZDZIARSKI, J. Aspects of genome plasticity in pathogenic Escherichia coli. Int. J. Med. Microbiol., v.297, p.625-639, 2007a. 
BIELASZEWSKA, M.; MIDDENDORF, B.; KOCK, R.; FRIEDRICH, A. W.; FRUTH, A.; KARCH, H.; SCHMIDT, M. A.; MELLMANN, A. Shiga toxinnegative attaching and effacing Escherichia coli: distinct clinical associations with bacterial phylogeny and virulence traits and inferred in-host pathogen evolution. Clin. Infect. Dis., v.47, p.208-217, 2008.

BIELASZEWSKA, M.; PRAGER, R.; KOCK, R.; MELLMANN, A.; ZHANG, W.; TSCHAPE, H.; TARR, P. I.; KARCH, H. Shiga toxin gene loss and transfer in vitro and in vivo during enterohemorrhagic Escherichia coli O26 infection in humans. Appl. Environ. Microbiol., v.73, p.3144-3150, 2007b.

BIELASZEWSKA, M.; SONNTAG, A. K.; SCHMIDT, M. A.; KARCH, H. Presence of virulence and fitness gene modules of enterohemorrhagic Escherichia coli in atypical enteropathogenic Escherichia coli O26. Microbes Infect., v.9, p.891-897, 2007c.

BLANCO, M.; BLANCO, J. E.; DAHBI, G.; MORA, A.; ALONSO, M. P.; VARELA, G.; GADEA, M. P.; SCHELOTTO, F.; GONZALEZ, E. A.; BLANCO, J. Typing of intimin (eae) genes from enteropathogenic Escherichia coli (EPEC) isolated from children with diarrhoea in Montevideo, Uruguay: identification of two novel intimin variants (muB and xiR/beta2B). J. Med. Microbiol., v.55, p.1165-1174, 2006.

BLANCO, M.; BLANCO, J. E.; MORA, A.; REY, J.; ALONSO, J. M.; HERMOSO, M.; HERMOSO, J.; ALONSO, M. P.; DAHBI, G.; GONZALEZ, E. A.; BERNARDEZ, M. I.; BLANCO, J. Serotypes, virulence genes, and intimin types of Shiga toxin (verotoxin)-producing Escherichia coli isolates from healthy sheep in Spain. J. Clin. Microbiol., v.41, p.1351-1356, 2003.

BLANCO, M.; SCHUMACHER, S.; TASARA, T.; ZWEIFEL, C.; BLANCO, J. E.; DAHBI, G.; BLANCO, J.; STEPHAN, R. Serotypes, intimin variants and other virulence factors of eae positive Escherichia coli strains isolated from healthy cattle in Switzerland. Identification of a new intimin variant gene (eae-eta2). BMC Microbiol., v.5, p.23, 2005.

BOKETE, T. N.; WHITTAM, T. S.; WILSON, R. A.; CLAUSEN, C. R.; O'CALLAHAN, C. M.; MOSELEY, S. L.; FRITSCHE, T. R.; TARR, P. I. Genetic and phenotypic analysis of Escherichia coli with enteropathogenic characteristics isolated from Seattle children. J. Infect. Dis., v.175, p.13821389, 1997.

BORTOLINI, M. R.; TRABULSI, L. R.; KELLER, R.; FRANKEL, G.; SPERANDIO, V. Lack of expression of bundle-forming pili in some clinical isolates of enteropathogenic Escherichia coli (EPEC) is due to a conserved large deletion in the bfp operon. FEMS Microbiol. Lett., v.179, p.169-174, 1999. 
BRAY, J. Isolation of antigenically homogeneous strains of Bact. coli neopolitanum from summer diarrhoea of infants. J. Pathol. Bacteriol., v.57, p.239-247, 1945.

BUERIS, V.; SIRCILI, M. P.; TADDEI, C. R.; DOS SANTOS, M. F.; FRANZOLIN, M. R.; MARTINEZ, M. B.; FERRER, S. R.; BARRETO, M. L.; TRABULSI, L. R. Detection of diarrheagenic Escherichia coli from children with and without diarrhea in Salvador, Bahia, Brazil. Mem. Inst. Oswaldo Cruz, v.102, p.839-844, 2007.

CAMPOS, L. C.; FRANZOLIN, M. R.; TRABULSI, L. R. Diarrheagenic Escherichia coli categories among the traditional enteropathogenic E. coli $O$ serogroups - a review. Mem. Inst. Oswaldo Cruz, v.99, p.545-552, 2004.

CAMPOS, L. C.; WHITTAM, T. S.; GOMES, T. A.; ANDRADE, J. R.; TRABULSI, L. R. Escherichia coli serogroup O111 includes several clones of diarrheagenic strains with different virulence properties. Infect. Immun., v.62, p.3282-3288, 1994.

CANTOR, G. H.; NELSON, S., JR.; VANEK, J. A.; EVERMANN, J. F.; ERIKS, I. S.; BASARABA, R. J.; BESSER, T. E. Salmonella spp. shedding in racing sled dogs. J. Vet. Diagn. Invest., v.9, p.447-448, 1997.

CARVALHO, V. M.; GYLES, C. L.; ZIEBELL, K.; RIBEIRO, M. A.; CATAODIAS, J. L.; SINHORINI, I. L.; OTMAN, J.; KELLER, R.; TRABULSI, L. R.; PESTANA DE CASTRO, A. F. Characterization of monkey enteropathogenic Escherichia coli (EPEC) and human typical and atypical EPEC serotype isolates from neotropical nonhuman primates. J. Clin. Microbiol., v.41, p.1225-1234, 2003.

CARVALHO, V. M.; IRINO, K.; ONUMA, D.; PESTANA DE CASTRO, A. F. Random amplification of polymorphic DNA reveals clonal relationships among enteropathogenic Escherichia coli isolated from non-human primates and humans. Braz. J. Med. Biol. Res., v.40, p.237-241, 2007.

CASTILLO, A.; EGUIARTE, L. E.; SOUZA, V. A genomic population genetics analysis of the pathogenic enterocyte effacement island in Escherichia coli: the search for the unit of selection. Proc. Natl. Acad. Sci. USA, v.102, p.15421547, 2005.

CHINA, B.; GOFFAUX, F.; PIRSON, V.; MAINIL, J. Comparison of eae, tir, espA and espB genes of bovine and human attaching and effacing Escherichia coli by multiplex polymerase chain reaction. FEMS Microbiol. Lett., v.178, p.177-182, 1999. 
CID, D.; RUIZ-SANTA-QUITERIA, J. A.; MARIN, I.; SANZ, R.; ORDEN, J. A.; AMILS, R.; DE LA FUENTE, R. Association between intimin (eae) and espB gene subtypes in attaching and effacing Escherichia coli strains isolated from diarrhoeic lambs and goat kids. Microbiology, v.147, p.2341-2353, 2001.

CLARKE, S. C. Diarrhoeagenic Escherichia coli - an emerging problem? Diagn. Microbiol. Infect. Dis., v.41, p.93-98, 2001.

CLEARY, J.; LAI, L. C.; SHAW, R. K.; STRAATMAN-IWANOWSKA, A.; DONNENBERG, M. S.; FRANKEL, G.; KNUTTON, S. Enteropathogenic Escherichia coli (EPEC) adhesion to intestinal epithelial cells: role of bundleforming pili (BFP), EspA filaments and intimin. Microbiology, v.150, p.527-538, 2004.

COOPER, J. E.; FEIL, E. J. Multilocus sequence typing--what is resolved? Trends Microbiol., v.12, p.373-377, 2004.

CRAVIOTO, A.; GROSS, R. J.; SCOTLAND, S.; ROWE, B. An adhesive factor found in strains of Escherichia coli belonging to the traditional infantile enteropathogenic serotypes. Curr. Microbiol., v.3, p.95 - 99, 1979.

CREASEY, E. A.; FRIEDBERG, D.; SHAW, R. K.; UMANSKI, T.; KNUTTON, S.; ROSENSHINE, I.; FRANKEL, G. CesAB is an enteropathogenic Escherichia coli chaperone for the type-III translocator proteins EspA and EspB. Microbiology, v.149, p.3639-3647, 2003.

CREPIN, V. F.; SHAW, R.; KNUTTON, S.; FRANKEL, G. Molecular basis of antigenic polymorphism of EspA filaments: development of a peptide display technology. J. Mol. Biol., v.350, p.42-52, 2005.

DEMING, M. S.; TAUXE, R. V.; BLAKE, P. A.; DIXON, S. E.; FOWLER, B. S.; JONES, T. S.; LOCKAMY, E. A.; PATTON, C. M.; SIKES, R. O. Campylobacter enteritis at a university: transmission from eating chicken and from cats. Am. J. Epidemiol., v.126, p.526-534, 1987.

DONNENBERG, M. S.; KAPER, J. B. Enteropathogenic Escherichia coli. Infect. Immun., v.60, p.3953-3961, 1992.

DONNENBERG, M. S.; WHITTAM, T. S. Pathogenesis and evolution of virulence in enteropathogenic and enterohemorrhagic Escherichia coli. J. Clin. Invest., v.107, p.539-548, 2001.

DRASSAR, B. S.; HILL, M. J. (Ed.). Human intestinal flora. London: Acad. Press, 1974. p.36-43. 
DULGUER, M. V.; FABBRICOTTI, S. H.; BANDO, S. Y.; MOREIRA-FILHO, C. A.; FAGUNDES-NETO, U.; SCALETSKY, I. C. Atypical enteropathogenic Escherichia coli strains: phenotypic and genetic profiling reveals a strong association between enteroaggregative $E$. coli heat-stable enterotoxin and diarrhea. J. Infect. Dis., v.188, p.1685-1694, 2003.

DURIEZ, P.; ZHANG, Y.; LU, Z.; SCOTT, A.; TOPP, E. Loss of virulence genes in Escherichia coli populations during manure storage on a commercial swine farm. Appl. Environ. Microbiol., v.74, p.3935-3942, 2008.

ELLIOTT, S. J.; WAINWRIGHT, L. A.; MCDANIEL, T. K.; JARVIS, K. G.; DENG, Y. K.; LAI, L. C.; MCNAMARA, B. P.; DONNENBERG, M. S.; KAPER, J. $B$. The complete sequence of the locus of enterocyte effacement (LEE) from enteropathogenic Escherichia coli E2348/69. Mol. Microbiol., v.28, p.1-4, 1998.

ESTRADA-GARCIA, T.; LOPEZ-SAUCEDO, C.; THOMPSON-BONILLA, R.; ABONCE, M.; LOPEZ-HERNANDEZ, D.; SANTOS, J. I.; ROSADO, J. L.; DUPONT, H. L.; LONG, K. Z. Association of diarrheagenic Escherichia coli Pathotypes with infection and diarrhea among Mexican children and association of atypical Enteropathogenic E. coli with acute diarrhea. J. Clin. Microbiol., v.47, p.93-98, 2009.

FIELDS, P. I.; BLOM, K.; HUGHES, H. J.; HELSEL, L. O.; FENG, P.; SWAMINATHAN, B. Molecular characterization of the gene encoding $\mathrm{H}$ antigen in Escherichia coli and development of a PCR-restriction fragment length polymorphism test for identification of E. coli O157:H7 and 0157:NM. J. Clin. Microbiol., v.35, p.1066-1070, 1997.

FITZHENRY, R. J.; PICKARD, D. J.; HARTLAND, E. L.; REECE, S.; DOUGAN, G.; PHILLIPS, A. D.; FRANKEL, G. Intimin type influences the site of human intestinal mucosal colonisation by enterohaemorrhagic Escherichia coli O157:H7. Gut, v.50, p.180-185, 2002a.

FITZHENRY, R. J.; REECE, S.; TRABULSI, L. R.; HEUSCHKEL, R.; MURCH, S.; THOMSON, M.; FRANKEL, G.; PHILLIPS, A. D. Tissue tropism of enteropathogenic Escherichia coli strains belonging to the 055 serogroup. Infect. Immun., v.70, p.4362-4368, 2002b.

FORESTIER, C.; MEYER, M.; FAVRE-BONTE, S.; RICH, C.; MALPUECH, G.; LE BOUGUENEC, C.; SIROT, J.; JOLY, B.; DE CHAMPS, C. Enteroadherent Escherichia coli and diarrhea in children: a prospective case-control study. $\mathbf{J}$. Clin. Microbiol., v.34, p.2897-2903, 1996.

FRANKE, J.; FRANKE, S.; SCHMIDT, H.; SCHWARZKOPF, A.; WIELER, L. H.; BALJER, G.; BEUTIN, L.; KARCH, H. Nucleotide sequence analysis of enteropathogenic Escherichia coli (EPEC) adherence factor probe and development of PCR for rapid detection of EPEC harboring virulence plasmids.

J. Clin. Microbiol., v.32, p.2460-2463, 1994. 
FRANKEL, G.; CANDY, D. C.; EVEREST, P.; DOUGAN, G. Characterization of the C-terminal domains of intimin-like proteins of enteropathogenic and enterohemorrhagic Escherichia coli, Citrobacter freundii, and Hafnia alvei. Infect. Immun., v.62, p.1835-1842, 1994.

FRANKEL, G.; CANDY, D. C.; FABIANI, E.; ADU-BOBIE, J.; GIL, S.; NOVAKOVA, M.; PHILLIPS, A. D.; DOUGAN, G. Molecular characterization of a carboxy-terminal eukaryotic-cell-binding domain of intimin from enteropathogenic Escherichia coli. Infect. Immun., v.63, p.4323-4328, 1995.

FRANKEL, G.; PHILLIPS, A. D.; ROSENSHINE, I.; DOUGAN, G.; KAPER, J. B.; KNUTTON, S. Enteropathogenic and enterohaemorrhagic Escherichia coli: more subversive elements. Mol. Microbiol., v.30, p.911-921, 1998.

FRANZOLIN, M. R.; ALVES, R. C.; KELLER, R.; GOMES, T. A.; BEUTIN, L.; BARRETO, M. L.; MILROY, C.; STRINA, A.; RIBEIRO, H.; TRABULSI, L. R. Prevalence of diarrheagenic Escherichia coli in children with diarrhea in Salvador, Bahia, Brazil. Mem. Inst. Oswaldo Cruz, v.100, p.359-363, 2005.

GARRIDO, P.; BLANCO, M.; MORENO-PAZ, M.; BRIONES, C.; DAHBI, G.; BLANCO, J.; PARRO, V. STEC-EPEC oligonucleotide microarray: a new tool for typing genetic variants of the LEE pathogenicity island of human and animal Shiga toxin-producing Escherichia coli (STEC) and enteropathogenic E. coli (EPEC) strains. Clin. Chem., v.52, p.192-201, 2006.

GOERING, R. V. Pulsed-field gel electrophoresis. In: PERSING, D. H. (Ed.). Molecular Microbiology: Diagnostic Principles and Practice. Washington: ASM Press, 2004. p.185-196.

GOFFAUX, F.; CHINA, B.; JANSSEN, L.; MAINIL, J. Genotypic characterization of enteropathogenic Escherichia coli (EPEC) isolated in Belgium from dogs and cats. Res. Microbiol., v.151, p.865-871, 2000.

GONCALVES, A. G.; CAMPOS, L. C.; GOMES, T. A.; RODRIGUES, J.; SPERANDIO, V.; WHITTAM, T. S.; TRABULSI, L. R. Virulence properties and clonal structures of strains of Escherichia coli $\mathrm{O} 119$ serotypes. Infect. Immun., v.65, p.2034-2040, 1997.

GUNZBURG, S. T.; TORNIEPORTH, N. G.; RILEY, L. W. Identification of enteropathogenic Escherichia coli by PCR-based detection of the bundleforming pilus gene. J. Clin. Microbiol., v.33, p.1375-1377, 1995.

HALL, B. G. (Ed.). Phylogenetics trees made easy. A how to manual for molecular biologists. Massachusetts: Sinauer Associates, 2001. p.179. 
HANAGE, P.; FEIL, E. J.; BRUEGGEMANN, A. B.; SPRATT, B. G. Multilocus Sequence Typing: Strain Characterization, Population Biology, and Patterns of Evolution Descent. In: PERSING, D. H. (Ed.). Molecular Microbiology: Diagnostic Principles and Practice. Washington: ASM Press, 2004. p.235-243.

HARBOTTLE, H.; WHITE, D. G.; MCDERMOTT, P. F.; WALKER, R. D.; ZHAO, $S$. Comparison of multilocus sequence typing, pulsed-field gel electrophoresis, and antimicrobial susceptibility typing for characterization of Salmonella enterica serotype Newport isolates. J. Clin. Microbiol., v.44, p.2449-2457, 2006.

HEDBERG, C. W.; SAVARINO, S. J.; BESSER, J. M.; PAULUS, C. J.; THELEN, V. M.; MYERS, L. J.; CAMERON, D. N.; BARRETT, T. J.; KAPER, J. B.; OSTERHOLM, M. T. An outbreak of foodborne illness caused by Escherichia coli O39:NM, an agent not fitting into the existing scheme for classifying diarrheogenic E. coli. J. Infect. Dis., v.176, p.1625-1628, 1997.

HERNANDES, R. T.; ELIAS, W. P.; VIEIRA, M. A.; GOMES, T. A. An overview of atypical enteropathogenic Escherichia coli. FEMS Microbiol. Lett., v.297, p.137-149, 2009.

HUELSENBECK, J. P.; RONQUIST, F. MRBAYES: Bayesian inference of phylogenetic trees. Bioinformatics, v.17, p.754-755, 2001.

HUSON, D. H. SplitsTree: analyzing and visualizing evolutionary data. Bioinformatics, v.14, p.68-73, 1998.

HUSON, D. H.; BRYANT, D. Application of phylogenetic networks in evolutionary studies. Mol. Biol. Evol., v.23, p.254-267, 2006.

HUSSEIN, H. S.; BOLLINGER, L. M. Prevalence of Shiga toxin-producing Escherichia coli in beef cattle. J. Food. Prot., v.68, p.2224-2241, 2005.

IDE, T.; LAARMANN, S.; GREUNE, L.; SCHILLERS, H.; OBERLEITHNER, H.; SCHMIDT, M. A. Characterization of translocation pores inserted into plasma membranes by type III-secreted Esp proteins of enteropathogenic Escherichia coli. Cell Microbiol., v.3, p.669-679, 2001.

ISHII, S.; MEYER, K. P.; SADOWSKY, M. J. Relationship between phylogenetic groups, genotypic clusters, and virulence gene profiles of Escherichia coli strains from diverse human and animal sources. Appl. Environ. Microbiol., v.73, p.5703-5710, 2007.

JARVIS, K. G.; GIRON, J. A.; JERSE, A. E.; MCDANIEL, T. K.; DONNENBERG, M. S.; KAPER, J. B. Enteropathogenic Escherichia coli contains a putative type III secretion system necessary for the export of proteins involved in attaching and effacing lesion formation. Proc. Natl. Acad. Sci. USA, v.92, p.7996-8000, 1995. 
JENKINS, C.; LAWSON, A. J.; CHEASTY, T.; WILLSHAW, G. A.; WRIGHT, P.; DOUGAN, G.; FRANKEL, G.; SMITH, H. R. Subtyping intimin genes from enteropathogenic Escherichia coli associated with outbreaks and sporadic cases in the United Kingdom and Eire. Mol. Cell Probes, v.17, p.149-156, 2003.

JERSE, A. E.; KAPER, J. B. The eae gene of enteropathogenic Escherichia coli encodes a 94-kilodalton membrane protein, the expression of which is influenced by the EAF plasmid. Infect. Immun., v.59, p.4302-4309, 1991.

JERSE, A. E.; YU, J.; TALL, B. D.; KAPER, J. B. A genetic locus of enteropathogenic Escherichia coli necessary for the production of attaching and effacing lesions on tissue culture cells. Proc. Natl. Acad. Sci. USA, v.87, p.7839-7843, 1990.

JI, R.; LI, Y. J.; WANG, Y. P.; CUI, S. H.; JIANG, T. Comparison of multilocus sequence typing system and pulsed-field gel electrophoresis in typing of Salmonella enteritidis. Zhonghua Liu Xing Bing Xue Za Zhi, v.27, p.10651068, 2006.

JOHNSON, J. R.; JOHNSTON, B.; CLABOTS, C. R.; KUSKOWSKI, M. A.; ROBERTS, E.; DEBROY, C. Virulence genotypes and phylogenetic background of Escherichia coli serogroup $\mathrm{O} 6$ isolates from humans, dogs, and cats. J. Clin. Microbiol., v.46, p.417-422, 2008a.

JOHNSON, J. R.; OWENS, K.; GAJEWSKI, A.; CLABOTS, C. Escherichia coli colonization patterns among human household members and pets, with attention to acute urinary tract infection. J. Infect. Dis., v.197, p.218-224, 2008b.

KAPER, J. B. Defining EPEC. Rev. Microbiol., v.27, p.3, 1996.

KAPER, J. B.; NATARO, J. P.; MOBLEY, H. L. Pathogenic Escherichia coli. Nat. Rev. Microbiol., v.2, p.123-140, 2004.

KAPPERUD, G.; SKJERVE, E.; BEAN, N. H.; OSTROFF, S. M.; LASSEN, J. Risk factors for sporadic Campylobacter spp. infections: results of a casecontrol study in southeastern Norway. J. Clin. Microbiol., v.30, p.3117-3121, 1992.

KENNY, B. Phosphorylation of tyrosine 474 of the enteropathogenic Escherichia coli (EPEC) Tir receptor molecule is essential for actin nucleating activity and is preceded by additional host modifications. Mol. Microbiol., v.31, p.1229-1241, 1999. 
KENNY, B.; DEVINNEY, R.; STEIN, M.; REINSCHEID, D. J.; FREY, E. A.; FINLAY, B. B. Enteropathogenic E. coli (EPEC) transfers its receptor for intimate adherence into mammalian cells. Cell, v.91, p.511-520, 1997.

KENNY, B.; FINLAY, B. B. Protein secretion by enteropathogenic Escherichia coli is essential for transducing signals to epithelial cells. Proc. Natl. Acad. Sci. USA, v.92, p.7991-7995, 1995.

KENNY, B.; LAI, L. C.; FINLAY, B. B.; DONNENBERG, M. S. EspA, a protein secreted by enteropathogenic Escherichia coli, is required to induce signals in epithelial cells. Mol. Microbiol., v.20, p.313-323, 1996.

KENNY, B.; WARAWA, J. Enteropathogenic Escherichia coli (EPEC) Tir receptor molecule does not undergo full modification when introduced into host cells by EPEC-independent mechanisms. Infect. Immun., v.69, p.1444-1453, 2001.

KNUTTON, S.; ROSENSHINE, I.; PALLEN, M. J.; NISAN, I.; NEVES, B. C.; BAIN, C.; WOLFF, C.; DOUGAN, G.; FRANKEL, G. A novel EspA-associated surface organelle of enteropathogenic Escherichia coli involved in protein translocation into epithelial cells. EMBO J., v.17, p.2166-2176, 1998.

KRAUSE, G.; ZIMMERMANN, S.; BEUTIN, L. Investigation of domestic animals and pets as a reservoir for intimin- (eae) gene positive Escherichia coli types. Vet. Microbiol., v.106, p.87-95, 2005.

LARKIN, M. A.; BLACKSHIELDS, G.; BROWN, N. P.; CHENNA, R.; MCGETTIGAN, P. A.; MCWILLIAM, H.; VALENTIN, F.; WALLACE, I. M.; WILM, A.; LOPEZ, R.; THOMPSON, J. D.; GIBSON, T. J.; HIGGINS, D. G. Clustal W and Clustal $X$ version 2.0. Bioinformatics, v.23, p.2947-2948, 2007.

LEOMIL, L.; AIDAR-UGRINOVICH, L.; GUTH, B. E.; IRINO, K.; VETTORATO, M. P.; ONUMA, D. L.; DE CASTRO, A. F. Frequency of Shiga toxin-producing Escherichia coli (STEC) isolates among diarrheic and non-diarrheic calves in Brazil. Vet. Microbiol., v.97, p.103-109, 2003.

LEOMIL, L.; PESTANA DE CASTRO, A. F.; KRAUSE, G.; SCHMIDT, H.; BEUTIN, L. Characterization of two major groups of diarrheagenic Escherichia coli O26 strains which are globally spread in human patients and domestic animals of different species. FEMS Microbiol. Lett., v.249, p.335-342, 2005.

LEVINE, M. M.; EDELMAN, R. Enteropathogenic Escherichia coli of classic serotypes associated with infant diarrhea: epidemiology and pathogenesis. Epidemiol. Rev., v.6, p.31-51, 1984. 
MACHADO, J.; GRIMONT, F.; GRIMONT, P. A. Identification of Escherichia coli flagellar types by restriction of the amplified fliC gene. Res. Microbiol., v.151, p.535-546, 2000.

MAIDEN, M. C.; BYGRAVES, J. A.; FEIL, E.; MORELLI, G.; RUSSELL, J. E.; URWIN, R.; ZHANG, Q.; ZHOU, J.; ZURTH, K.; CAUGANT, D. A.; FEAVERS, I. M.; ACHTMAN, M.; SPRATT, B. G. Multilocus sequence typing: a portable approach to the identification of clones within populations of pathogenic microorganisms. Proc. Natl. Acad. Sci. USA, v.95, p.3140-3145, 1998.

MAIRENA, E. C.; NEVES, B. C.; TRABULSI, L. R.; ELIAS, W. P. Detection of LEE 4 region-encoded genes from different enteropathogenic and enterohemorrhagic Escherichia coli serotypes. Curr. Microbiol., v.48, p.412418, 2004.

MCDANIEL, T. K.; JARVIS, K. G.; DONNENBERG, M. S.; KAPER, J. B. A genetic locus of enterocyte effacement conserved among diverse enterobacterial pathogens. Proc. Natl. Acad. Sci. USA, v.92, p.1664-1668, 1995.

MELLMANN, A.; BIELASZEWSKA, M.; KARCH, H. Intrahost genome alterations in enterohemorrhagic Escherichia coli. Gastroenterology, v.136, p.1925-1938, 2009.

MELLMANN, A.; BIELASZEWSKA, M.; ZIMMERHACKL, L. B.; PRAGER, R.; HARMSEN, D.; TSCHAPE, H.; KARCH, H. Enterohemorrhagic Escherichia coli in human infection: in vivo evolution of a bacterial pathogen. Clin. Infect. Dis., v.41, p.785-792, 2005.

MICHINO, H.; ARAKI, K.; MINAMI, S.; TAKAYA, S.; SAKAI, N.; MIYAZAKI, M.; ONO, A.; YANAGAWA, H. Massive outbreak of Escherichia coli O157:H7 infection in schoolchildren in Sakai City, Japan, associated with consumption of white radish sprouts. Am. J. Epidemiol., v.150, p.787-796, 1999.

MOON, H. W.; WHIPP, S. C.; ARGENZIO, R. A.; LEVINE, M. M.; GIANNELLA, R. A. Attaching and effacing activities of rabbit and human enteropathogenic Escherichia coli in pig and rabbit intestines. Infect. Immun., v.41, p.1340-1351, 1983.

MORATO, E. P.; LEOMIL, L.; BEUTIN, L.; KRAUSE, G.; MOURA, R. A.; PESTANA DE CASTRO, A. F. Domestic Cats Constitute a Natural Reservoir of Human Enteropathogenic Escherichia coli Types. Zoo. Public Health, v.56, p.229-237, 2008. 
MOREIRA, F. C.; VIEIRA, M. A.; FERREIRA, A. J.; GIRAO, D. M.; VAZ, T. M.; ROSA, A. C.; KNOBL, T.; IRINO, K.; FREYMULLER, E.; GOMES, T. A. Escherichia coli strains of serotype O51:H40 comprise typical and atypical enteropathogenic $E$. coli strains and are potentially diarrheagenic. J. Clin. Microbiol., v.46, p.1462-1465, 2008.

MORENO, A. C.; FILHO, A. F.; GOMES, T. D.; RAMOS, S. T.; MONTEMOR, L. P.; TAVARES, V. C.; FILHO, L. D.; IRINO, K.; MARTINEZ, M. B. Etiology of childhood diarrhea in the northeast of Brazil: significant emergent diarrheal pathogens. Diagn. Microbiol. Infect. Dis., 2008.

MUNDY, R.; SCHULLER, S.; GIRARD, F.; FAIRBROTHER, J. M.; PHILLIPS, A. D.; FRANKEL, G. Functional studies of intimin in vivo and ex vivo: implications for host specificity and tissue tropism. Microbiology, v.153, p.959-967, 2007.

NAKAZATO, G.; GYLES, C.; ZIEBELL, K.; KELLER, R.; TRABULSI, L. R.; GOMES, T. A.; IRINO, K.; DA SILVEIRA, W. D.; PESTANA DE CASTRO, A. F. Attaching and effacing Escherichia coli isolated from dogs in Brazil: characteristics and serotypic relationship to human enteropathogenic E. coli (EPEC). Vet. Microbiol., v.101, p.269-277, 2004.

NATARO, J. P.; KAPER, J. B. Diarrheagenic Escherichia coli. Clin. Microbiol. Rev., v.11, p.142-201, 1998.

NEMOY, L. L.; KOTETISHVILI, M.; TIGNO, J.; KEEFER-NORRIS, A.; HARRIS, A. D.; PERENCEVICH, E. N.; JOHNSON, J. A.; TORPEY, D.; SULAKVELIDZE, A.; MORRIS, J. G., JR.; STINE, O. C. Multilocus sequence typing versus pulsed-field gel electrophoresis for characterization of extended-spectrum betalactamase-producing Escherichia coli isolates. J. Clin. Microbiol., v.43, p.17761781, 2005.

NETER, E.; WESTPHAL, O.; LUDERITZ, O.; GINO, R. M.; GORZYNSKI, E. A. Demonstration of antibodies against enteropathogenic Escherichia coli in sera of children of various ages. Pediatrics, v.16, p.801-808, 1955.

NEVES, B. C.; KNUTTON, S.; TRABULSI, L. R.; SPERANDIO, V.; KAPER, J. B.; DOUGAN, G.; FRANKEL, G. Molecular and ultrastructural characterisation of EspA from different enteropathogenic Escherichia coli serotypes. FEMS Microbiol. Lett., v.169, p.73-80, 1998.

NEVES, B. C.; SHAW, R. K.; FRANKEL, G.; KNUTTON, S. Polymorphisms within EspA filaments of enteropathogenic and enterohemorrhagic Escherichia coli. Infect. Immun., v.71, p.2262-2265, 2003.

NGUYEN, R. N.; TAYLOR, L. S.; TAUSCHEK, M.; ROBINS-BROWNE, R. M. Atypical enteropathogenic Escherichia coli infection and prolonged diarrhea in children. Emerg. Infect. Dis., v.12, p.597-603, 2006. 
NIELSEN, E. M.; ANDERSEN, M. T. Detection and characterization of verocytotoxin-producing Escherichia coli by automated 5' nuclease PCR assay. J. Clin. Microbiol., v.41, p.2884-2893, 2003.

NYLANDER, J. A.; RONQUIST, F.; HUELSENBECK, J. P.; NIEVES-ALDREY, J. L. Bayesian phylogenetic analysis of combined data. Syst. Biol., v.53, p.4767, 2004.

OCHOA, T. J.; BARLETTA, F.; CONTRERAS, C.; MERCADO, E. New insights into the epidemiology of enteropathogenic Escherichia coli infection. Trans. R. Soc. Trop. Med. Hyg., v.102, p.852-856, 2008.

O'CONNELL, C. B.; CREASEY, E. A.; KNUTTON, S.; ELLIOTT, S.; CROWTHER, L. J.; LUO, W.; ALBERT, M. J.; KAPER, J. B.; FRANKEL, G.; DONNENBERG, M. S. SepL, a protein required for enteropathogenic Escherichia coli type III translocation, interacts with secretion component SepD. Mol. Microbiol., v.52, p.1613-1625, 2004.

OOKA, T.; VIEIRA, M. A.; OGURA, Y.; BEUTIN, L.; LA RAGIONE, R.; VAN DIEMEN, P. M.; STEVENS, M. P.; AKTAN, I.; CAWTHRAW, S.; BEST, A.; HERNANDES, R. T.; KRAUSE, G.; GOMES, T. A.; HAYASHI, T.; FRANKEL, G. Characterization of tccP2 carried by atypical enteropathogenic Escherichia coli. FEMS Microbiol. Lett., v.271, p.126-135, 2007.

ØRSKOV, F.; ØRSKOV, I. Serotyping of Escherichia coli. In: BERGAN, T. (Ed.). Methods in Microbiology. New York: Acad. Press, 1984. p.43-112.

OSWALD, E.; SCHMIDT, H.; MORABITO, S.; KARCH, H.; MARCHES, O.; CAPRIOLI, A. Typing of intimin genes in human and animal enterohemorrhagic and enteropathogenic Escherichia coli: characterization of a new intimin variant. Infect. Immun., v.68, p.64-71, 2000.

PAULOZZI, L. J.; JOHNSON, K. E.; KAMAHELE, L. M.; CLAUSEN, C. R.; RILEY, L. W.; HELGERSON, S. D. Diarrhea associated with adherent enteropathogenic Escherichia coli in an infant and toddler center, Seattle, Washington. Pediatrics, v.77, p.296-300, 1986.

PEIXOTO, J. C.; BANDO, S. Y.; ORDONEZ, J. A.; BOTELHO, B. A.; TRABULSI, L. R.; MOREIRA-FILHO, C. A. Genetic differences between Escherichia coli O26 strains isolated in Brazil and in other countries. FEMS Microbiol. Lett., v.196, p.239-244, 2001.

PELAYO, J. S.; SCALETSKY, I. C.; PEDROSO, M. Z.; SPERANDIO, V.; GIRON, J. A.; FRANKEL, G.; TRABULSI, L. R. Virulence properties of atypical EPEC strains. J. Med. Microbiol., v.48, p.41-49, 1999. 
PENTEADO, A. S.; UGRINOVICH, L. A.; BLANCO, J.; BLANCO, M.; BLANCO, J. E.; MORA, A.; ANDRADE, J. R.; CORREA, S. S.; PESTANA DE CASTRO, A. F. Serobiotypes and virulence genes of Escherichia coli strains isolated from diarrheic and healthy rabbits in Brazil. Vet. Microbiol., v.89, p.41-51, 2002.

PERSING, D. H (Ed.). Molecular microbiology: diagnostic principles and practice. Washington: ASM Press, 2004. cap.15, p.185-196.

PHILLIPS, A. D.; FRANKEL, G. Intimin-mediated tissue specificity in enteropathogenic Escherichia coli interaction with human intestinal organ cultures. J. Infect. Dis., v.181, p.1496-1500, 2000.

POSADA, D. Using MODELTEST and PAUP* to select a model of nucleotide substitution. Curr. Protoc. Bioinformatics, cap. 6, 2003.

POSADA, D.; CRANDALL, K. A. MODELTEST: testing the model of DNA substitution. Bioinformatics, v.14, p.817-818, 1998.

POSPISCHIL, A.; MAINIL, J. G.; BALJER, G.; MOON, H. W. Attaching and effacing bacteria in the intestines of calves and cats with diarrhea. Vet. Pathol., v.24, p.330-334, 1987.

PRAGER, R.; FRUTH, A.; SIEWERT, U.; STRUTZ, U.; TSCHAPE, H. Escherichia coli encoding Shiga toxin $2 f$ as an emerging human pathogen. Int. J. Med. Microbiol., v.299, p.343-353, 2009.

RAMOS MORENO, A. C.; CABILIO GUTH, B. E.; BAQUERIZO MARTINEZ, M. Can the fliC PCR-restriction fragment length polymorphism technique replace classic serotyping methods for characterizing the $\mathrm{H}$ antigen of enterotoxigenic Escherichia coli strains? J. Clin. Microbiol., v.44, p.1453-1458, 2006.

RATCHTRACHENCHAI, O. A.; SUBPASU, S.; HAYASHI, H.; BA-THEIN, W. Prevalence of childhood diarrhoea-associated Escherichia coli in Thailand. J. Med. Microbiol., v.53, p.237-243, 2004.

RIBOT, E. M.; FAIR, M. A.; GAUTOM, R.; CAMERON, D. N.; HUNTER, S. B.; SWAMINATHAN, B.; BARRETT, T. J. Standardization of pulsed-field gel electrophoresis protocols for the subtyping of Escherichia coli O157:H7, Salmonella spp., and Shigella spp. for PulseNet. Foodborne Pathog. Dis., v.3, p.59-67, 2006.

ROBINS-BROWNE, R. M.; BORDUN, A. M.; TAUSCHEK, M.; BENNETTWOOD, V. R.; RUSSELL, J.; OPPEDISANO, F.; LISTER, N. A.; BETTELHEIM, K. A.; FAIRLEY, C. K.; SINCLAIR, M. I.; HELLARD, M. E. Escherichia coli and community-acquired gastroenteritis, Melbourne, Australia. Emerg. Infect. Dis., v.10, p.1797-1805, 2004. 
ROBINS-BROWNE, R. M.; HARTLAND, E. L. Escherichia coli as a cause of diarrhea. J. Gastroenterol. Hepatol., v.17, p.467-475, 2002.

ROBINSON, R. A.; PUGH, R. N. Dogs, zoonoses and immunosuppression. J. R. Soc. Promot. Health, v.122, p.95-98, 2002.

RODRIGUES, J.; SCALETSKY, I. C.; CAMPOS, L. C.; GOMES, T. A.; WHITTAM, T. S.; TRABULSI, L. R. Clonal structure and virulence factors in strains of Escherichia coli of the classic serogroup 055. Infect. Immun., v.64, p.2680-2686, 1996.

RODRIGUES, J.; THOMAZINI, C. M.; LOPES, C. A.; DANTAS, L. O. Concurrent infection in a dog and colonization in a child with a human enteropathogenic Escherichia coli clone. J. Clin. Microbiol., v.42, p.1388-1389, 2004.

RONQUIST, F.; HUELSENBECK, J. P. MrBayes 3: Bayesian phylogenetic inference under mixed models. Bioinformatics, v.19, p.1572-1574, 2003.

ROWE, B. The role of Escherichia coli in gastroenteritis. Clin. Gastroenterol., v.8, p.625-644, 1979.

SALFIELD, N. J.; PUGH, E. J. Campylobacter enteritis in young children living in households with puppies. Br. Med. J., v.294, p.21-22, 1987.

SAMBROOK, J.; RUSSELL, D. W. (Ed.). The condensed protocols from Molecular cloning: a laboratory manual. New York: Cold Spring Harbor Laboratory Press, 2006. p.309-312.

SATO, Y.; MORI, T.; KOYAMA, T.; NAGASE, H. Salmonella virchow infection in an infant transmitted by household dogs. J. Vet. Med. Sci., v.62, p.767-769, 2000.

SCALETSKY, I. C.; FABBRICOTTI, S. H.; CARVALHO, R. L.; NUNES, C. R.; MARANHAO, H. S.; MORAIS, M. B.; FAGUNDES-NETO, U. Diffusely adherent Escherichia coli as a cause of acute diarrhea in young children in Northeast Brazil: a case-control study. J. Clin. Microbiol., v.40, p.645-648, 2002.

SCALETSKY, I. C.; PEDROSO, M. Z.; OLIVA, C. A.; CARVALHO, R. L.; MORAIS, M. B.; FAGUNDES-NETO, U. A localized adherence-like pattern as a second pattern of adherence of classic enteropathogenic Escherichia coli to HEp-2 cells that is associated with infantile diarrhea. Infect. Immun., v.67, p.3410-3415, 1999.

SCHMIDT, H.; BEUTIN, L.; KARCH, H. Molecular analysis of the plasmidencoded hemolysin of Escherichia coli O157:H7 strain EDL 933. Infect. Immun., v.63, p.1055-1061, 1995. 
SCHMIDT, H.; SCHEEF, J.; MORABITO, S.; CAPRIOLI, A.; WIELER, L. H.; $\mathrm{KARCH}, \mathrm{H}$. A new Shiga toxin 2 variant (Stx2f) from Escherichia coli isolated from pigeons. Appl. Environ. Microbiol., v.66, p.1205-1208, 2000.

SCHWARTZ, D. C.; SAFFRAN, W.; WELSH, J.; HAAS, R.; GOLDENBERG, M.; CANTOR, C. R. New techniques for purifying large DNAs and studying their properties and packaging. Cold. Spring. Harb. Symp. Quant. Biol., v.47, p.189-195, 1983.

SCOTLAND, S. M.; SMITH, H. R.; CHEASTY, T.; SAID, B.; WILLSHAW, G. A.; STOKES, N.; ROWE, B. Use of gene probes and adhesion tests to characterise Escherichia coli belonging to enteropathogenic serogroups isolated in the United Kingdom. J. Med. Microbiol., v.44, p.438-443, 1996.

SINCLAIR, J. F.; O'BRIEN, A. D. Intimin types alpha, beta, and gamma bind to nucleolin with equivalent affinity but lower avidity than to the translocated intimin receptor. J. Biol. Chem., v.279, p.33751-33758, 2004.

SMITH, H.; SCOTLAND, S.; CHEASTY, T.; WILLSHAW, G.; ROWE, B. Enteropathogenic Escherichia coli infections in the United Kingdom. Rev. Microbiol., v.27, 1996.

TAMURA, K.; DUDLEY, J.; NEI, M.; KUMAR, S. MEGA4: Molecular Evolutionary Genetics Analysis (MEGA) software version 4.0. Mol. Biol. Evol., v.24, p.1596-1599, 2007.

TARR, C. L.; WHITTAM, T. S. Molecular evolution of the intimin gene in 0111 clones of pathogenic Escherichia coli. J. Bacteriol., v.184, p.479-487, 2002.

TENNANT, S. M.; TAUSCHEK, M.; AZZOPARDI, K.; BIGHAM, A.; BENNETTWOOD, V.; HARTLAND, E. L.; QI, W.; WHITTAM, T. S.; ROBINS-BROWNE, R. $M$. Characterisation of atypical enteropathogenic $E$. coli strains of clinical origin. BMC Microbiol., v.9, p.117, 2009.

TORRES, A. G.; ZHOU, X.; KAPER, J. B. Adherence of diarrheagenic Escherichia coli strains to epithelial cells. Infect. Immun., v.73, p.18-29, 2005.

TRABULSI, L. R.; CAMPOS, L.; WHITTAM, T.; GOMES, T.; RODRIGUES, J.; GONÇALVES, A. Traditional and non-traditional enteropathogenic Escherichia coli serogroups. Rev. Microbiol., v.27, p.1-6, 1996.

TRABULSI, L. R.; KELLER, R.; TARDELLI GOMES, T. A. Typical and atypical enteropathogenic Escherichia coli. Emerg. Infect. Dis., v.8, p.508-513, 2002. 
TSAI, H. J.; HUANG, H. C.; TSAI, H. L.; CHANG, C. C. PCR-based restriction fragment length polymorphism (RFLP) analysis of Campylobacter jejuni isolates from humans, chickens and dogs in northern Taiwan. J. Vet. Med. Sci., v.68, p.815-819, 2006.

USEIN, C. R.; TATU-CHITOIU, D.; CIONTEA, S.; CONDEI, M.; DAMIAN, M. Escherichia coli pathotypes associated with diarrhea in Romanian children younger than 5 years of age. Jpn. J. Infect. Dis., v.62, p.289-293, 2009.

VALLE, G. R.; GOMES, T. A.; IRINO, K.; TRABULSI, L. R. The traditional enteropathogenic Escherichia coli (EPEC) serogroup 0125 comprises serotypes which are mainly associated with the category of enteroaggregative E. coli. FEMS Microbiol. Lett., v.152, p.95-100, 1997.

VETTORATO, M. P.; LEOMIL, L.; GUTH, B. E.; IRINO, K.; PESTANA DE CASTRO, A. F. Properties of Shiga toxin-producing Escherichia coli (STEC) isolates from sheep in the State of Sao Paulo, Brazil. Vet. Microbiol., v.95, p.103-109, 2003.

VIDAL, M.; KRUGER, E.; DURAN, C.; LAGOS, R.; LEVINE, M.; PRADO, V.; TORO, C.; VIDAL, R. Single multiplex PCR assay to identify simultaneously the six categories of diarrheagenic Escherichia coli associated with enteric infections. J. Clin. Microbiol., v.43, p.5362-5365, 2005.

VIEIRA, M. A.; ANDRADE, J. R.; TRABULSI, L. R.; ROSA, A. C.; DIAS, A. M.; RAMOS, S. R.; FRANKEL, G.; GOMES, T. A. Phenotypic and genotypic characteristics of Escherichia coli strains of non-enteropathogenic $E$. coli (EPEC) serogroups that carry EAE and lack the EPEC adherence factor and Shiga toxin DNA probe sequences. J. Infect. Dis., v.183, p.762-772, 2001.

VILJANEN, M. K.; PELTOLA, T.; JUNNILA, S. Y.; OLKKONEN, L.; JARVINEN, H.; KUISTILA, M.; HUOVINEN, P. Outbreak of diarrhoea due to Escherichia coli O111:B4 in schoolchildren and adults: association of $\mathrm{Vi}$ antigen-like reactivity. Lancet, v.336, p.831-834, 1990.

WARAWA, J.; KENNY, B. Phosphoserine modification of the enteropathogenic Escherichia coli Tir molecule is required to trigger conformational changes in Tir and efficient pedestal elongation. Mol. Microbiol., v.42, p.1269-1280, 2001.

WHITTAM, T. S.; MCGRAW, T. E. A. Clonal analysis of EPEC serogroups. Rev. Microbiol. , v.27, p.7-16, 1996.

WHITTAM, T. S.; WOLFE, M. L.; WACHSMUTH, I. K.; ORSKOV, F.; ORSKOV, I.; WILSON, R. A. Clonal relationships among Escherichia coli strains that cause hemorrhagic colitis and infantile diarrhea. Infect. Immun., v.61, p.16191629, 1993. 
WILGENBUSCH, J. C.; SWOFFORD, D. Inferring evolutionary trees with PAUP* ${ }^{\star}$. Curr. Protoc. Bioinformatics, Cap. 6: Unit:6.4, 2003.

XIA, X.; XIE, Z. DAMBE: software package for data analysis in molecular biology and evolution. J. Hered., v.92, p.371-373, 2001.

YAMAMOTO, T.; WAKISAKA, N.; SATO, F.; KATO, A. Comparison of the nucleotide sequence of enteroaggregative Escherichia coli heat-stable enterotoxin 1 genes among diarrhea-associated Escherichia coli. FEMS Microbiol. Lett., v.147, p.89-95, 1997.

YATSUYANAGI, J.; SAITO, S.; MIYAJIMA, Y.; AMANO, K.; ENOMOTO, K. Characterization of atypical enteropathogenic Escherichia coli strains harboring the astA gene that were associated with a waterborne outbreak of diarrhea in Japan. J. Clin. Microbiol., v.41, p.2033-2039, 2003.

YUSTE, M.; DE LA FUENTE, R.; RUIZ-SANTA-QUITERIA, J. A.; CID, D.; ORDEN, J. A. Detection of the astA (EAST1) gene in attaching and effacing Escherichia coli from ruminants. J. Vet. Med., v.53, p.75-77, 2006. 